\title{
Relationship between Maternal Booking Visit Lipid Profile and Placental Morphometric Outcome in the Kumasi Metropolis, Ghana
}

\author{
Samuel Bimpong1 ${ }^{*}$, Chrissie Stansie Abaidoo ${ }^{2}$, Eric Faakuu1 ${ }^{1}$, Emmanuel Kwaku Osabutey ${ }^{1}$ \\ ${ }^{1}$ Department of Anatomy, School of Medicine, University for Development Studies, Tamale, Ghana \\ ${ }^{2}$ Department of Anatomy, School of Medical Sciences, Kwame Nkrumah University of Science and Technology, Kumasi, Ghana \\ Email: ^sbimpong@uds.edu.gh,chrissiestansieabaidoo@yahoo.co.uk,efaakuu@uds.edu.gh, eosabutey@uds.edu.gh
}

How to cite this paper: Bimpong, S., Abaidoo, C.S., Faakuu, E. and Osabutey, E.K. (2021) Relationship between Maternal Booking Visit Lipid Profile and Placental Morphometric Outcome in the Kumasi Metropolis, Ghana. Open Access Library Journal, 8: e7876.

https://doi.org/10.4236/oalib.1107876

Received: August 20, 2021

Accepted: October 25, 2021

Published: October 28, 2021

Copyright $\odot 2021$ by author(s) and Open Access Library Inc.

This work is licensed under the Creative Commons Attribution International License (CC BY 4.0).

http://creativecommons.org/licenses/by/4.0/

\begin{abstract}
Background: The significance of investigating relationships involved in the transport of lipids to the foetus is very important in the first-trimester embryogenesis. The objective of this study, therefore, was to model the relationship between the maternal booking visit lipid profile parameters and the placental indices outcomes. Method: Analytical descriptive cross-sectional study was conducted between March 2014 and October 2018 on placenta, neonates and maternal booking visit lipid profile parameters. A total of 240 pregnant women who attended antenatal care at the Victory Maternity Home and Clinic in Kumasi for the first time and consented to participate were enrolled in the study. Maternal booking lipid profile parameters including; total cholesterol (TC), triglyceride (TG), high-density lipoprotein cholesterol (HDL-C), and low-density lipoprotein cholesterol (LDL-C) were obtained on their first antenatal clinic (ANC) visit. Blood samples were collected from the participants for serum preparation and analysis. Results: The mean value for placental weight in the current study was $502.40 \pm 103.70 \mathrm{~g}(95 \% \mathrm{CI}=489.20$ 515.60). Mean values of placental diameter and thickness were $19.01 \pm 2.41$ $\mathrm{cm}(95 \% \mathrm{CI}$ of $18.71-19.32)$ and $2.85 \pm 0.53 \mathrm{~cm}$ (95\% CI of $2.78-2.92)$, respectively. All the booking visit lipids, namely TC, TG, HDL-C and LDL-C significantly influenced the placental volume $(\mathrm{p}<0.05)$. Conclusion: It was found that all the maternal booking visit lipids (TC, TG, HDL-C and LDL-C) could jointly predict the outcome of placental volume.
\end{abstract}

\section{Subject Areas}

Women's Health

\section{Keywords}

Lipid Profile, Pillai’s Test Statistic, Lipoprotein, Booking Visit, Placenta, 
Cholesterol, Triglyceride

\section{Introduction}

A maternal booking visit defined as the first visit of a pregnant woman to the maternity unit of a hospital, clinic or health center is usually described as a booking visit (BV). It happens to be the first encounter with healthcare providers as well as being introduced to maternity services [1]. It is also the time when both obstetric and family histories are recorded for the purposes of determining any potential health risk during pregnancy. The antenatal period offers the best of times for the pregnant woman to access both preventive and curative health care [2]. It is a component of the Safe Motherhood Programme proven to increase the quality of pregnancy outcomes [3].

Normal pregnancy is characterized by rising levels of maternal serum total cholesterol (TC), low-density lipoprotein cholesterol (LDL-C), high-density lipoprotein cholesterol (HDL-C) and triglyceride (TG) [4]. Physiologically, cholesterol is an essential structural component of the plasma membrane, modulates metabolism and serves as precursors of steroid hormones in pregnancy, while the cholesterol is delivered to the materno-foetal transport system via LDL receptors across the placental border to support foetal growth and development through activation and propagation of hedgehog signalling [5]. The transfer of cholesterol from maternal LDL and HDL across the placenta requires the use of $\mathrm{LDL}$ receptors and scavenger receptor $\mathrm{B} 1$ (SR-B1) in that order and reaches the foetal HDL by the use of ATP binding cassette (ABC) G1 and ABCA1 [6].

Low or high maternal serum cholesterol concentrations during pregnancy are known to associate with certain disease states or conditions. For instance, pregnant women with abetalipoproteinaemia, hypobetalipoproteinaemia or those who take in a low cholesterol diet possess extreme to moderate low plasma cholesterol concentrations during pregnancy. Similarly, pregnant women with high maternal circulating cholesterol concentrations develop hypercholesterolaemia in the third trimester [7].

The significance of studying relationships involved in the transport of cholesterol to foetus is as important in the first-trimester embryogenesis as the full complementary growth and development of organ systems of the foetus observed in the third trimester [8]. Importantly, the reported high levels of HDL-C and LDL-C in umbilical cord venous plasma are attributed to an increase in placental permeability leading to efflux of cholesterol into foetal circulation [9].

The transfer capacity of the placenta could be modulated by several mechanisms including placental morphometry (surface area, thickness, weight, etc.), an abundance of transporter activity and expressions, substrate availability and establishment of the concentration gradient between maternal and foetal circulations. Increased cholesterol and triglyceride concentrations in both maternal and foetal compartments result in high levels of placental fatty acid transporters 
in the cotyledons while expression and activities of some nutrient transporters such as glucose transporters become affected by maternal metabolism [10].

Following inconsistencies and complexity of placental morphologic studies, quantitative assessment of the placenta has become the best way to understand the range of functions in relation to the structure of this haemochorial and deciduate organ. A significant reduction in surface area, volume and weight of the placenta results in the slow transfer of essential nutrients to the developing foetus which most often than not leads to stillbirth, a characteristic common in hypertensive pregnant women [11]. Therefore, the objective of this study is to establish a relationship between maternal booking visit lipid profile parameters and placental indices outcomes.

\section{Materials and Methods}

\subsection{Study Design}

Analytical descriptive cross sectional study was conducted between March 2014 and October 2018 on placenta, neonates and maternal booking biometric indices. A total of 240 pregnant women who attended antenatal care (ANC) at the Victory Maternity Home and Clinic in Kumasi for the first time and consented to participate were enrolled into the study.

\subsection{Inclusion and Exclusion Criteria}

\subsubsection{Inclusion Criteria}

Included in the study were:

1) Mothers who consented to the collection of blood samples in order to avoid ethical violations;

2) Mothers who had singleton pregnancy with no pregnancy or delivery complications since the study design did not take into consideration multiple births and birth related complications;

3) Mothers from whom the antennal and maternity records about themselves and their neonates were complete to avoid misinformation.

\subsubsection{Exclusion Criteria}

Excluded from the study were:

1) Mothers who did not consent to the blood sample collection;

2) Mothers who had multiple births and with pregnancy or delivery complications;

3) Also, mothers with incomplete antenatal and maternity records about themselves and their neonates.

\subsection{Study Variables}

The study variables were categorized into placental and maternal booking biometric indices. After sample preparations, the under listed parameters were measured.

\subsubsection{Placental Indices}

The following placental measurements were made on the gross structure: 
1) Weight of placenta: It was measured using an electronic weighing scale (OIML Electronic Waterproof Weighing Scale-AIPI-SS2, China) and recorded with accuracy of 0.10 after the umbilical cord was cut and the placental membranes trimmed. The placenta was then placed on the scale. The weighing was repeated and the average of the two weights was taken as the weight of placenta.

2) Volume of placenta: This was obtained by the use of water displacement method and recorded in accuracy of $0.1 \mathrm{~mL}$. The placenta was gently lowered into transparent graduated beaker (1000 litres capacity) containing water. The initial water volume $V_{1}$ was noted, and final volume $V_{2}$ after putting in the placenta was also recorded. The difference between $V_{2}$ and $V_{1}$ then gave the volume of water displaced and that also became the volume of the placenta.

3) Diameter of Placenta: This was measured with a non-elastic measuring tape with accuracy of $1 \mathrm{~cm}$. Measurement across both the largest and smallest diameters were made. The average of largest $\left(D_{1}\right)$ and smallest $\left(D_{2}\right)$ diameters was taken as the diameter $(D)$ of the placenta.

4) Surface Area: The maternal surface area of the placenta was computed using the formula:

Surface area $=\frac{\pi D_{1} \times D_{2}}{4}$, (where $D_{1}$ is the largest diameter and $D_{2}$ is the smallest diameter).

5) Placental Thickness: The placenta was placed on a flat surface and a thin long graduated needle was inserted into the placenta, at the centre, at the margin and midway between the centre and margin. The average of the three recordings was taken as the thickness of the placenta which was analyzed in units of 0.10 .

\subsubsection{Maternal Booking Biometric Indices}

Maternal booking lipid profile parameters included; TC, TG, HDL-C, LDL-C, systolic and diastolic blood pressures which were obtained on their first ANC visit. Two hundred and forty blood samples were collected after an overnight fast of at least 12 hours into a $3.5 \mathrm{ml}$ vacutainer (BD Plymouth, SST II Advance Tubes, UK) and were stored at temperature of $-80^{\circ} \mathrm{C}$ in an ice-packed vaccine box and transported to the Wenchi Methodist Hospital Laboratory for the serum preparation and analysis. Serum and plasma were stored at $-80^{\circ} \mathrm{C}$ after centrifugation at $2000 \mathrm{~g}$ for 5 minutes until assaying. Fasting blood TC, TG and HDL-C were measured on Automated Chemistry Analyzer (Flexor junior, Vital Scientific N.V., The Netherland) with reagents from ELITech Group company, (SEPPIM S.A.S, France). The LDL-C was calculated using the Friedewald equation incorporated in the auto-analyzer as follows:

$\mathrm{LDL}-\mathrm{C}(\mathrm{mmol} / \mathrm{L})=[\mathrm{TC}(\mathrm{mmol} / \mathrm{L})-(\mathrm{TG}(\mathrm{mmol} / \mathrm{L}) / 2.2+\mathrm{HDL}-\mathrm{C}(\mathrm{mmol} / \mathrm{L})]$.

\subsection{Statistical Analysis}

Mean value \pm SD was used for the descriptive characteristics of the study variables. Multivariate analysis of variance (MANOVA) was employed to model as- 
sociation between maternal booking biometric and placental measurements.

First, correlation structure and cross correlations were developed to establish relationships between the maternal and placental data sets. The correlations between the variables were described as weak or strong with regards to the correlation coefficient value. The models were then developed using step by step approach of multivariate analysis of variance. Six placental indices were modelled jointly with six predictors of maternal biometric indices using multivariate linear regression. P-value $<0.05$ was considered statistically significant. Type II MANOVA tests: Pillai's test statistics and a post hoc MANOVA procedure called descriptive discriminant analysis (DDA) were used to refit the final model. The models are presented with coefficients, standard error (SE), $t$-value and model $p$-value < 0.05 for each predictor. The basic multivariate linear regression model containing standardized regression coefficients in predicting the corresponding outcome of the response variable is generally expressed as:

$$
\hat{\gamma}=\hat{\beta}_{0}+\hat{\beta}_{1} x_{1}+\hat{\beta}_{2} x_{2}+\hat{\beta}_{3} x_{3}+\cdots+\hat{\beta}_{k} x_{k}
$$

where

$\hat{y}$ is the predicted response variable.

$\hat{\beta}_{1 \cdots k}$ are the estimated regression coefficients.

$\hat{\beta}_{0}$ is the intercept when all of the explanatory variables are equal to zero.

$x_{i}(i=1, \cdots, k)$ is the estimated explanatory variable.

In this study all statistical analyses were performed with IBM SPSS Version 22.0 (SPSS Inc. Chicago, IL).

\section{Results}

\subsection{Demographic and Clinical Characteristics of Study Participants}

Maternal demographic and clinical characteristics are shown in Table 1 . The mean maternal age was $27.42 \pm 6.10$ years (range: $15-43$ years) and that of parity was $2.57 \pm 1.42$ births (range: 1 - 8 births). Mean gestational age was $36.60 \pm$ 2.46 weeks (range: 24 - 50 weeks). The mean maternal booking weight was 66.26 $\pm 11.17 \mathrm{~kg}(37-95 \mathrm{~kg})$. The mean maternal height was $1.60 \pm 0.07 \mathrm{~m}(1.30-1.80$ $\mathrm{m})$. The mean waist circumference was $50.12 \pm 12.08 \mathrm{~cm}(32-89 \mathrm{~cm})$. Maternal booking BMI had mean of $25.80 \pm 4.44 \mathrm{~kg} / \mathrm{m}^{2}\left(14.81-41.42 \mathrm{~kg} / \mathrm{m}^{2}\right)$.

The mean values of maternal prepregnancy systolic and diastolic blood pressures were $118.81 \pm 25.15 \mathrm{mmHg}$ (range: $90-250 \mathrm{mmHg}$ ) and $75.04 \pm 14.02$ $\mathrm{mmHg}$ (range: $50-120 \mathrm{mmHg}$ ) respectively. Total cholesterol and triglycerides had their respective mean and range to be $4.02 \pm 0.09 \mathrm{mmol} / \mathrm{L}$ (range: $1.40-9.15$ $\mathrm{mmol} / \mathrm{L}$ ) and $1.47 \pm 0.05 \mathrm{mmol} / \mathrm{L}$ (range: $0.38-6.92 \mathrm{mmol} / \mathrm{L}$ ). Similarly, the mean HDL-C was $1.11 \pm 0.47 \mathrm{mmol} / \mathrm{L}$ (range: $0.50-2.98 \mathrm{mmol} / \mathrm{L}$ ). The LDL-C mean was $2.24 \pm 0.83 \mathrm{mmol} / \mathrm{L}$ (range: $0.36-5.68 \mathrm{mmol} / \mathrm{L}$ ).

\subsection{Descriptive Statistics of Placental Indices for Modelling}

The mean value for placental weight in this current study was $502.40 \pm 103.70 \mathrm{~g}$ 
(95\% CI $=489.20-515.60)$. Mean values of placental diameter and thickness were $19.01 \pm 2.41 \mathrm{~cm}(95 \% \mathrm{CI}$ of $18.71-19.32)$ and $2.85 \pm 0.53 \mathrm{~cm}(95 \% \mathrm{CI}$ of 2.78 - 2.92), respectively. Placental area and volume recorded mean values of $287.40 \pm 74.28 \mathrm{~cm}^{2}$ and $623.20 \pm 109.80 \mathrm{~cm}^{3}(95 \% \mathrm{CI}=278.00-296.90$ and 609.20 - 637.10) respectively. The mean number of cotyledons was $16.99 \pm 3.47$ (95\% CI of $16.55-17.43$ ) as shown in Table 2.

\subsection{Pearson Correlation between Placental and Maternal Booking Biometric Indices}

Pearson cross correlation between placental and maternal booking measurements

Table 1. Descriptive statistics of maternal demographic and clinical characteristics.

\begin{tabular}{ccc}
\hline Characteristic & Mean \pm SD & Range \\
\hline Age (Years) & $27.42 \pm 6.10$ & $15-43$ \\
Parity & $2.57 \pm 1.42$ & $1-8$ \\
MWt $(\mathrm{kg})$ & $66.26 \pm 11.17$ & $37-95$ \\
MHt $(\mathrm{m})$ & $1.60 \pm 0.07$ & $1.30-1.80$ \\
MWC $(\mathrm{cm})$ & $50.12 \pm 12.08$ & $32-89$ \\
BMI $\left(\mathrm{kg} / \mathrm{m}^{2}\right)$ & $25.80 \pm 4.44$ & $14.81-41.42$ \\
SBP $(\mathrm{mmHg})$ & $118.81 \pm 25.15$ & $90-250$ \\
DBP $(\mathrm{mmHg})$ & $75.04 \pm 14.02$ & $50-120$ \\
TC $(\mathrm{mmol} / \mathrm{L})$ & $4.02 \pm 0.09$ & $1.40-9.15$ \\
TG $(\mathrm{mmol} / \mathrm{L})$ & $1.47 \pm 0.05$ & $0.38-6.92$ \\
HDL-C $(\mathrm{mmol} / \mathrm{L})$ & $1.11 \pm 0.47$ & $0.05-2.98$ \\
LDL-C (mmol/L) & $2.24 \pm 0.83$ & $0.36-5.68$ \\
\hline
\end{tabular}

$\mathrm{MWt}=$ maternal booking weight; $\mathrm{MHt}=$ maternal Height; $\mathrm{MWC}=$ maternal booking waist circumference; $\mathrm{MHC}=$ maternal hip circumference; $\mathrm{SD}=$ standard deviation; $\mathrm{cm}=$ centimeter $\mathrm{m}=$ meter; $\mathrm{SBP}=$ systolic blood pressure; $\mathrm{DBP}=$ diastolic blood pressure; $\mathrm{TC}=$ total cholesterol; $\mathrm{TG}=$ triglycerides; $\mathrm{HDL}-\mathrm{C}=$ high density lipoprotein; $\mathrm{LDL}-\mathrm{C}=$ low density lipoprotein; $\mathrm{mmHg}=$ millimeter mercury; $\mathrm{mmol} / \mathrm{L}=$ millimole per liter.

Table 2. Descriptive statistics of placental measurements.

\begin{tabular}{cccc}
\hline Variables & Mean \pm SD & Range & $\begin{array}{c}\text { 95\% CI of Mean } \\
\text { Lower - Upper 95\% CI }\end{array}$ \\
\hline PW $(\mathrm{g})$ & $502.40 \pm 103.70$ & $274.20-781.70$ & $489.20-515.60$ \\
PD $(\mathrm{cm})$ & $19.01 \pm 2.41$ & $13.50-27.50$ & $18.71-19.32$ \\
PT $(\mathrm{cm})$ & $2.85 \pm 0.53$ & $1.80-4.05$ & $2.78-2.92$ \\
PAREA $\left(\mathrm{cm}^{2}\right)$ & $287.40 \pm 74.28$ & $133.60-592.40$ & $278.00-296.90$ \\
PV $\left(\mathrm{cm}^{3}\right)$ & $623.20 \pm 109.80$ & $275.30-834.80$ & $609.20-637.10$ \\
P COTYL & $16.99 \pm 3.47$ & $9.00-27.00$ & $16.55-17.43$ \\
\hline
\end{tabular}

PW= Placental Weight; PD = Placental Diameter; PT = Placental Thickness; PAREA = Area of Placenta; PV $=$ Volume of Placenta; PCOTYL $=$ Number of Placental Cotyledons; $95 \%$ CI $=95 \%$ Confidence Interval of Mean. 
showed very weak correlations. From Table 3, maternal booking HDL showed a weak positive correlation with all the placental indices, similar to maternal total cholesterol which exhibited negative correlation with only the number of placental cotyledons.

Maternal booking triglyceride correlated negatively with placental diameter, thickness, volume and number of cotyledons, but related positively with placental weight and area. Also, LDL exhibited negative correlations with placental area and number of cotyledons while showing positive relationship with placental weight, diameter, thickness and volume.

\subsection{Placental and Maternal Booking Lipid Profile Indices Modeling}

The intergroup mean differences of the data were established using multivariate analysis of variance (MANOVA) techniques. To start with, the individual placental response variables (weight, diameter, thickness, area, volume and number of cotyledons) were analyzed against the four maternal booking visit lipid profile parameters (explanatory variables) using multivariate linear regression as shown in Table 4.

Table 3. Pearson cross correlation between placental indices and maternal booking biometric parameters.

\begin{tabular}{ccccc}
\hline Variables & Mcholesterol (R=) & Mtriglyceride (R=) & MHDL (R=) & MLDL (R=) \\
\hline PW & 0.052 & 0.022 & 0.029 & 0.026 \\
PD & 0.020 & -0.002 & 0.027 & 0.003 \\
PA & 0.005 & 0.001 & 0.013 & -0.010 \\
PT & 0.064 & -0.039 & 0.081 & 0.054 \\
PV & 0.053 & -0.007 & 0.029 & 0.032 \\
Pcot & -0.025 & -0.168 & 0.142 & -0.052 \\
\hline
\end{tabular}

$\mathrm{R}=$ Correlation coefficient $\mathrm{PW}=$ placental weight $\mathrm{PD}=$ Placental diameter; $\mathrm{PA}=$ Area of Placenta; $\mathrm{PT}=$ Placental thickness; PV = Placental volume; Pcot $=$ Number of cotyledon; Mcholesterol = Maternal booking cholesterol; Mtriglyderide = Maternal booking triglyceride; $\mathrm{MHDL}=$ Maternal booking high density lipoprotein; MLDL = Maternal booking low density lipoprotein.

Table 4. Multivariate regression models for placental and maternal booking biometrics indices.

\begin{tabular}{ccccccc}
\hline Predictor & $\begin{array}{c}\mathbf{P}_{\mathrm{W}} \\
\text { EST(SE) }\end{array}$ & $\begin{array}{c}\mathbf{P}_{\mathrm{D}} \\
\text { EST(SE) }\end{array}$ & $\begin{array}{c}\mathbf{P}_{\mathrm{A}} \\
\text { EST(SE) }\end{array}$ & $\begin{array}{c}\mathbf{P}_{\mathrm{T}} \\
\text { EST(SE) }\end{array}$ & $\begin{array}{c}\mathbf{P}_{\mathrm{V}} \\
\text { EST(SE) }\end{array}$ & $\begin{array}{c}\mathbf{N}_{\mathrm{COT}} \\
\text { EST(SE) }\end{array}$ \\
\hline Intercept & $505.591(46.999)$ & $19.600(1.095)$ & $306.906(33.689)$ & $29.465(2.340)$ & $647.179(49.725)$ & $17.904(1.519)$ \\
$\mathbf{M}_{\mathrm{TC}}$ & $61.911(42.397)$ & $0.670(0.988)$ & $19.363(30.396)$ & $0.647(2.165)$ & $96.270(44.864)^{*}$ & $1.067(1.370)$ \\
$\mathbf{M}_{\mathrm{TG}}$ & $-24.725(21.090)$ & $-0.314(0.492)$ & $-9.023(15.120)$ & $-0.510(1.077)$ & $-44.755(22.317)^{*}$ & $-1.172(0.682)$ \\
$\mathbf{M}_{\mathrm{HDL}}$ & $-54.944(43.467)$ & $-0.560(1.013)$ & $-17.420(31.163)$ & $0.088(2.220)$ & $-88.662(45.996)^{*}$ & $0.071(1.405)$ \\
$\mathbf{M}_{\mathrm{LDL}}$ & $-58.471(42.858)$ & $-0.669(0.999)$ & $-20.302(30.727)$ & $-0.446(2.189)$ & $-91.394(45.352)^{*}$ & $-1.589(1.385)$ \\
\hline
\end{tabular}

$\mathrm{P}_{\mathrm{W}}=$ placental weight; $\mathrm{P}_{\mathrm{D}}=$ Placental diameter $\mathrm{P}_{\mathrm{A}}=$ Area of Placenta; $\mathrm{P}_{\mathrm{T}}=$ Placental thickness; $\mathrm{P}_{\mathrm{V}}=$ Placental volume; $\mathrm{N}_{\mathrm{COT}}=$ Number of cotyledon; $\mathrm{M}_{\mathrm{SBP}}=$ Maternal booking systolic blood pressure; $\mathrm{M}_{\mathrm{DBP}}=$ Maternal booking diastolic blood pressure; $\mathrm{M}_{\mathrm{TC}} \mathrm{l}=$ Maternal booking cholesterol; $\mathrm{M}_{\mathrm{TG}}=\mathrm{Maternal}_{\text {booking }}$ triglyceride; $\mathrm{M}_{\mathrm{HDL}}=$ Maternal booking high density lipoprotein; $\mathrm{M}_{\mathrm{LDL}}=$ Maternal booking low density lipoprotein; EST = Estimation; $\mathrm{SE}=$ standard error; ${ }^{*} \mathrm{p}<0.05$. 
From Table 4, the joint effects of the maternal booking lipid profile parameters on placental volume in the multivariate linear regression models could be expressed in mathematical equation as:

$$
\mathrm{P}_{\mathrm{V}}=647.179+96.270 \mathrm{M}_{\mathrm{TC}}-44.755 \mathrm{M}_{\mathrm{TG}}-88.662 \mathrm{M}_{\mathrm{HDL}}-91.394 \mathrm{M}_{\mathrm{LDL}},(\mathrm{p}<0.05) \text {, }
$$

where $\mathrm{M}_{\mathrm{TC}}$ is maternal total cholesterol, $\mathrm{M}_{\mathrm{TG}}$ is the maternal triglyceride, $\mathrm{M}_{\mathrm{HDL}}$ is the maternal high-density lipoprotein and $\mathrm{M}_{\mathrm{LDL}}$ is the maternal low-density lipoprotein.

In order to evaluate the performance of the multivariate linear regression models in predicting the outcome of the placental indices, a robust Type II MANOVA test-Pillai's test statistic was used. The result of the Pillai's test statistic is presented in Table 5. Even though there were statistically significant, the joint effect of maternal TC, TG, HDL-C and LDL-C on placental variables as observed in Table 5, the Pillai's test statistic thus shows that none of the maternal biometric variables could independently predict the outcome of any of the placenta variables.

\section{Discussion}

\subsection{Descriptive Statistics of Placental and Maternal Booking Biometric Indices}

The present study found the mean values of placental weight, diameter and thickness to be $502.40 \pm 103.70 \mathrm{~g}, 19.01 \pm 2.41 \mathrm{~cm}$ and $2.85 \pm 0.53 \mathrm{~cm}$ respectively. The mean placental area, volume and number of cotyledons were also recorded as $287.40 \pm 74.28 \mathrm{~cm}^{2}, 623.20 \pm 109.80 \mathrm{~cm}^{3}$ and $16.99 \pm 1.47$ in that order. These values demonstrate that morphological characteristics of the studied placentae were normal. The finding of this present report is comparable to the results of placental morphology outcome in preeclampsia and normotensive pregnancy study which recorded mean placental weight of $502.00 \pm 58.42 \mathrm{~g}$, and diameter of $18.70 \pm 1.55 \mathrm{~cm}$. Likewise, the mean thickness was estimated to be $2.30 \pm 0.43 \mathrm{~cm}$ and number of cotyledons to be $18.90 \pm 1.98$ for the control group as these values were higher than that of the study group [12]. In another study, the mean placenta weight, area and volume were also recorded as $401.80 \pm$

Table 5. Type II MANOVA Tests: Pillai's test statistic on maternal booking biometrics and placental parameters.

\begin{tabular}{ccccccc}
\hline Predictors & Df & test stat & approx F & num Df & den Df & $\operatorname{Pr}(>$ F $)$ \\
\hline Mtcholesterol & 1 & 0.025206 & 1.00845 & 6 & 234 & 0.4204 \\
Mtriglyceride & 1 & 0.035737 & 1.44538 & 6 & 234 & 0.1981 \\
MHDL & 1 & 0.021250 & 0.84672 & 6 & 234 & 0.5350 \\
MLDL & 1 & 0.025771 & 1.03167 & 6 & 234 & 0.4053 \\
\hline
\end{tabular}

Mtcholesterol = Maternal total cholesterol; Mtriglyceride $=$ Maternal triglyceride; MHDL $=$ Maternal high, density lipoprotein; MLDL = Maternal low-density lipoprotein; Df = Degree of freedom; test stat = test, statistic, approx; F = approximation based on F-distribution; num Df = numerator degree of freedom; den Df $=$ denominator degree of freedom; $\operatorname{Pr}(>F)=$ significance level of F-ratio. 
$54.62 \mathrm{~g}, 212.48 \pm 54.51 \mathrm{~cm}^{2}$ and $439.48 \pm 135.14 \mathrm{~cm}^{3}$ respectively for the normotensives and these were also significantly higher than those in the study group [13]. The observed results of this current study and others confirm that, in normal pregnancies the morphometric parameters of placenta are higher than in complicated pregnancies.

In this current study, mean values of maternal booking lipid profile parameters included; total cholesterol, $1.48 \pm 0.77 \mathrm{mmol} / \mathrm{L}$ triglyceride, $1.11 \pm 0.47$ $\mathrm{mmol} / \mathrm{L}$ HDL-C and $2.24 \pm 0.84 \mathrm{mmol} / \mathrm{L}$ LDL-C. The observed mean values of maternal booking serum concentrations of TC, TG, HDL-C and LDL-C were lower than the first trimester mean values of maternal lipids recorded in other studies [14] [15] [16]. This is in line with the observations that, serum levels of maternal lipids increase significantly with advancement in gestation. The rise in concentration of maternal lipids as pregnancy progresses is attributed to the increased foetal energy demand on maternal metabolism. Thus, there is therefore a switch from carbohydrate metabolism in providing energy to lipid metabolism which serves as alternative energy pathway for the developing foetus. Also there is high demand for cholesterol in the synthesis of plasma membranes of the cells as organogenesis begins [16].

\subsection{Pearson Correlation between Placental and Maternal Booking Visit Lipid Profile Indices}

The relationships between placental indices and maternal booking biometric indices were found to be weakly correlated in the present study. Both TC and HDL showed positive correlation with almost all the placental indices with only TC relating negatively with number of placental cotyledons. The levels of TG correlated positively with only placental weight and area while correlating negatively with diameter, thickness, volume and number of cotyledons. The LDL levels negatively correlated with placental area and number of cotyledons but showed positive relation with the weight, diameter, thickness and volume.

It appears that currently there is little or no information on correlation between maternal booking visit lipid profile indices and placental morphometry as observed by the present study. However, maternal booking lipid profile parameters and pregnancy outcome have been extensively studied with the focus on its relationship with racial/ethnicity [17] [18], preterm birth [19], cardiovascular risks [20], gestational body mass index (BMI) and diabetes mellitus [21] [22] and birth indices [23], of such study used maternal measurements at first antenatal visit and found positive correlation of placental volume with maternal weight, BMI and haemoglobin [24]. Another study also reported that booking risk of cardiovascular incidence is likely to have adverse consequences on birth outcome as a result of dysfunctional placenta.

The weak non-significant correlations of this present study probably could mean that the booking visit biometric recordings at first antenatal visit set the preliminary stage for further progression of gestation. It is evident that maternal blood pressure and lipid levels increase with advancing gestation [25] [26], while 
the placenta begins to become fully functional after week 26 of gestation [27].

\subsection{Maternal Booking Visit Biometric and Placental Indices Modeling}

Following the weak Pearson correlations observed between maternal booking biometric measurements and placental morphometric indices in this study, the effects of interaction terms between maternal booking biometric and placental morphometric indices were tested by developing multivariate linear regression models for the prediction of successful outcome. Six models were fitted with placental response variables (weight, diameter, thickness, area, volume, number of cotyledons) against four maternal explanatory variables (TC, TG, HDL-C and LDL-C). Explanatory variable with $\mathrm{p}<0.05$ in at least one of the six models was included in a final model. The booking visit lipids namely TC, TG, HDL-C and LDL-C, all had significant joints effect on placental volume ( $\mathrm{p}<0.05)$. This implies that all maternal booking lipids could predict placental volume. The combined estimation of the joint effects between maternal booking biometric indices and other placental response variables however, were not significant.

In order to evaluate the performance of the multivariate linear regression models in the prediction of outcome of placental indices, a Type II MANOVA Test-Pillai's Test statistic was performed. Even though maternal booking lipids had significant joint effect on the placental volume, Pillai's Test statistics showed that none of booking lipids could independently predict the placental outcome. The findings of the present study probably add up to the growing body of evidence on the importance of placental transfer of these maternal fuels. Though the mechanism underlying the prediction of placental volume by these maternal booking lipids is not clear, it may be attributed to the availability and quantity of cholesterol transporters localized in the placenta. The placenta is key in the transfer of cholesterol from the mother to foetus and is known that in the first week of life, the foetus solely depends on maternal cholesterol as the main source of structural and functional development [5]. Placental trophoblast has been found to express significant level of low density lipoprotein (LDLR) receptors, very low-density lipoprotein (VLDLR) receptors, scavenger receptor class $B$ type I (SR B1) and Apo-protein B-100 (ApoB-100) with all of them facilitating the transportation of cholesterol to the foetus [28]. One study postulated that, early first trimester abnormal serum parameters directly related to abnormal placental morphometric variables culminating in poor perinatal outcome. It was realized that an abnormal early first trimester trophoblast invasion led to variations in the placental morphology [29]. Therefore, markers of early first trimester placental function are crucial in initiating maternal-foetal exchange in pregnancy.

Hence, the volume of placenta which is an indication of the amount of substances it contains including large amount of trophoblast cells could contribute to the serum lipid transport efficiency. Following scarcity of literature in relating placental volume to maternal booking lipids, it is tempting to speculate that, the prediction of placental volume by these maternal booking lipids clearly shows foetal 
dependency on maternal cholesterol supply during first trimester of gestation.

\section{Conclusions}

The mean values of placental indices observed in the current study were similar to the findings of studies of placentae from normal uncomplicated pregnancies. Also, the Pearson correlation structure developed for maternal booking visit lipid profile and placental indices showed weak relationships.

It was found that all maternal booking visit lipids (TC, TG, HDL-C, LDL-C) could jointly predict the outcome of placental volume. However, none of the individual lipids could predict the outcome of the placental volume independently.

The multivariate multiple regression equation for maternal booking visit lipids to predict placental volume is therefore expressed as:

$$
\mathrm{P}_{\mathrm{V}}=647.179+96.270 \mathrm{M}_{\mathrm{TC}}-44.755 \mathrm{M}_{\mathrm{TG}}-88.662 \mathrm{M}_{\mathrm{HDL}}-91.394 \mathrm{M}_{\mathrm{LDL}},(\mathrm{p}<0.05) \text {. }
$$

\section{Author's Contributions}

CSA planned, initiated and was involved in the analysis of the data, and led multiple reviews of the manuscript.

SB was involved in data collection, data analysis and drafting of the manuscript.

EF was involved in the writing and reviewing of the final paper and made useful suggestions for some of the practical aspects of the research.

EKO was involved in the laboratory measurements, data collection and the drafting of the manuscript.

\section{Acknowledgements}

This study was supported by the staff of Victory Maternity Home and Clinic in the sample collection process and the technical staff of the Anatomy department. Mr. Christopher Nkrumah of Wenchi Methodist Hospital Laboratory also needs a special mention in this paper for his guidance and direction.

\section{Conflicts of Interest}

The authors declare no conflicts of interest.

\section{References}

[1] Yeboah, F.A., Fondjo, L.A., Seini, M.M., Turpin, C.A., Debrah, O., Annan, B.R.D.T., Tagoe, E.A. and Bawah, A.T. (2018) Association between Antenatal Booking Visit and Occurrence of Preeclampsia: A Ghanaian Study. Edorium Journal of Gynecology and Obstetrics, 4, Article ID: 100020G06FY2018.

[2] Gudayu, T., Woldeyohannes, S. and Abdo, A. (2014) Timing and Factors Associated with First Antenatal Care Booking among Pregnant Mothers in Gondar Town; North West Ethiopia. BMC Pregnancy and Childbirth, 14, Article No. 287. https://doi.org/10.1186/1471-2393-14-287

[3] Asamoah, B. and Agardh, A. (2017) Inequality Trends in Maternal Health Services for Young Ghanaian Women with Childbirth History between 2003 and 2014. Brit- 
ish Medical Journal Open, 7, Article ID: e011663. https://doi.org/10.1136/bmjopen-2016-011663

[4] Sales, W., Dias Junior, S., Kroll, C., Mastroeni, S., Silva, F. and Mastroeni, M. (2015) Influence of Altered Maternal Lipid Profile on the Lipid Profile of the Newborn. Archives of Endocrinology and Metabolism, 59, 123-128. https://doi.org/10.1590/2359-3997000000024

[5] Zhang, R., Dong, S., Ma, W.-W., Cai, X.-P., Le, Z.-Y., Xiao, R., et al. (2017) Modulation of Cholesterol Transport by Maternal Hypercholesterolemia in Human Full-Term Placenta. PLoS ONE, 12, Article ID: e0171934.

https://doi.org/10.1371/journal.pone.0171934

[6] Huda, S., Sattar, N. and Freeman, D. (2009) Lipoprotein Metabolism and Vascular Complications in Pregnancy. Clinical Lipidology, 4, 92-102.

[7] Salameh, W. and Matrogiannis, D. (1994) Maternal Hyperlipidemia in Pregnancy. Clinical Obstetrics and Gynecology, 37, 66-77. https://doi.org/10.1097/00003081-199403000-00011

[8] Kallol, S., Huang, X., Müller, S., Ontsouka, C. and Albrecht, C. (2018) Novel Insights into Concepts and Directionality of Maternal-Fetal Cholesterol Transfer across the Human Placenta. International Journal of Molecular Science, 19, Article No. 2334. https://doi.org/10.3390/ijms19082334

[9] Frantz, E., Menezes, H., Lange, K., Abegg, M., Correa, C., Zangalli, L., Vieira, J. and Zettler, C. (2012) The Effect of Maternal Hypercholesterolemia on the Placenta and Fetal Arteries in Rabbits. Acta Cirúrgica Brasileira, 27, 7-12. https://doi.org/10.1590/S0102-86502012000100002

[10] Tarrade, A., Panchenko, P., Junien, C. and Gabory, A. (2015) Placental Contribution to Nutritional Programming of Health and Diseases: Epigenetics and Sexual Dimorphism. The Journal of Experimental Biology, 218, 50-58. https://doi.org/10.1242/jeb.110320

[11] Akshara, V., Ramakrishnan, P., Chitra, S., Kumar, S., Senthil Kumar, S. and Seema, V. (2018) Morphology and the Morphometric Measurements of Hypertensive and Normotensive Placenta. Biomedical Research, 29, Article No. 60.

[12] Shevade, S., Arole, V., Bharambe, V. and Paranjape, V. (2015) Placental Morphology and Fetal Outcome in Preeclampsia and Normotensive Pregnancies. IOSR Journal of Dental and Medical Sciences, 14, 11-15.

[13] Londhe, P. and Mane, A. (2011) Morphometric Study of Placenta and Its Correlation in Normal and Hypertensive Pregnancies. International Journal of Pharma and Bio Sciences, 2, 429-437.

[14] Jin, W.-Y., Lin, S.-L., Hou, R.-L., Chen, X.-Y., Han, T., Jin, Y., Tang. L., Zhu, Z.-W. and Zhao, Z.-Y. (2016) Associations between Maternal Lipid Profile and Pregnancy Complications and Perinatal Outcomes: A Population-Based Study from China. BMC Pregnancy and Childbirth, 16, Article No. 60. https://doi.org/10.1186/s12884-016-0852-9

[15] Boghossian, N., Mendola, P., Liu, A., Robledo, C. and Yeung, E. (2017) Maternal Serum Markers of Lipid Metabolism in Relation to Neonatal Anthropometry. Jounal of Perinatology, 37, 629-635. https://doi.org/10.1038/jp.2017.22

[16] Mishra, M., Sharma, R., Sharma, D., Mishra, A. and Sharma, D. (2017) Study of Variations in Lipid Profile in Different Trimesters of Pregnancy. International Journal of Medical Science and Public Health, 6, 456-459. https://doi.org/10.5455/ijmsph.2017.0525911052016

[17] Schreuder, Y., Hutten, B., van Eijsden, M., Jansen, E., Vissers, M., Twickler, M. and 
Vrijkotte, T. (2011) Ethnic Differences in Maternal Total Cholesterol and Triglyceride Levels during Pregnancy: The Contribution of Demographics, Behavioural Factors and Clinical Characteristics. European Journal of Clinical Nutrition, 65, 580-589. https://doi.org/10.1038/ejen.2010.282

[18] Frank, A., Beinan, Z., Powell, O., Azar, K., Fortmann, S. and Palaniappan, L. (2014) Racial/Ethnic Differences in Dyslipidemia Patterns. Circulation, 129, 570-579. https://doi.org/10.1161/CIRCULATIONAHA.113.005757

[19] Catov, J., Ness, R., Wellons, M., Jacobs, D. Roberts, J. and Gunderson, E. (2010) Prepregnancy Lipids Related to Preterm Birth Risk: The Coronary Artery Risk Development in Young Adults Study. Journal of Clinical Endocrinology and Metabolism, 95, 3711-3718. https://doi.org/10.1210/jc.2009-2028

[20] Harville, E., Myers, L., Shu, T., Wallace, M. and Bazzano, L. (2018) Pre-Pregnancy Cardiovascular Risk Factors and Racial Disparities in Birth Outcomes: The Bogalusa Heart Study. BMC Pregnancy and Childbirth, 18, Article No. 339.

https://doi.org/10.1186/s12884-018-1959-y

[21] Rebelo, F., Farias, D., Mendes, R., Schlüssel, M. and Kac, G. (2014) Blood Pressure Variation throughout Pregnancy According to Early Gestational BMI: A Brazilian Cohort. Arquivos Brasileiros de Cardiologia, 104, 284-291.

https://doi.org/10.5935/abc.20150007

[22] Wang, C., Zhu, W., Wei, Y., Su, R., Feng, H., Lin, L. and Yang. H. (2016) The Predictive Effects of Early Pregnancy Lipid Profiles and Fasting Glucose on the Risk of Gestational Diabetes Mellitus Stratified by Body Mass Index. Journal of Diabetes Research, 2016, Article ID: 2543268. https://doi.org/10.1155/2016/2543268

[23] Mitra, S., Misra, S., Nayak, P. and Sahoo, J. (2012) Effect of Maternal Anthropometry and Metabolic Parameters on Fetal Growth. Indian Journal of Endocrinology and Metabolism, 16, 754-758. https://doi.org/10.4103/2230-8210.100669

[24] Thame, M., Osmond, C., Wilks, R., Bennett, F., McFarlane-Anderson, N. and Forrester, T. (2000) Blood Pressure Is Related to Placental Volume and Birth Weight. Hypertension, 35, 662-667. https://doi.org/10.1161/01.HYP.35.2.662

[25] Grindheim G, Estensen M, Langesaeter E, Rosseland L and Toska K. (2012) Changes in Blood Pressure during Healthy Pregnancy: A Longitudinal Cohort study. Journal of Hypertension, 30, 342-350. https://doi.org/10.1097/HJH.0b013e32834f0b1c

[26] Leiva, A., Diez de Medina, C., Salsoso, R., Sáez, T., San Martín, S., Abarzúa, F., Farías, M., Guzmán-Gutiérrez, E., Pardo, F. and Sobrevia, L. (2013) Maternal Hypercholesterolemia in Pregnancy Associates with Umbilical Vein Endothelial Dysfunction Role of Endothelial Nitric Oxide Synthase and Arginase II. Arteriosclerosis, Thrombosis, and Vascular Biology, 33, 2444-2453.

https://doi.org/10.1161/ATVBAHA.113.301987

[27] Larsen, W. (2001) Human Embryology, 3rd Edition, Churchill Livingstone, New York.

[28] Zeng, Z., Liu, F. and Li, S. (2017) Metabolic Adaptations in Pregnancy: A Review. Annals of Nutrition and Metabolism, 70, 59-65. https://doi.org/10.1159/000459633

[29] Karmakar, M., Kumar, S., Chattopadhyay, S., Kar, S., Vaid, L. and Sen, S. (2018) A Study on the Morphology and the Morphometry of the Human Placenta and its Clinical Significance in Rural Population in Eastern India. Asian Pacific Journal of Health Science, 5, 202-209. 


\section{Abbreviations}

$\begin{array}{ll}\text { ABC A1 } & \text { ATP Binding Cassette A1 } \\ \text { ANC } & \text { Antenatal care } \\ \text { BV } & \text { Booking Visit } \\ \text { DDA } & \text { Descriptive Discriminant Analysis } \\ \text { HDL-C } & \text { High Density Lipoprotein-C holesterol } \\ \text { LDL-C } & \text { Low Density Lipoprotein-C holesterol } \\ \text { MANOVA } & \text { Multivariate Analysis of Variance } \\ \text { PA } & \text { Placental Area } \\ \text { P COT } & \text { Placental Cotyledon } \\ \text { PD } & \text { Placental Diameter } \\ \text { PT } & \text { Placental Thickness } \\ \text { PV } & \text { Placental Volume } \\ \text { PW } & \text { Placental weight } \\ \text { SR-B1 } & \text { Scavenger Receptor B1 } \\ \text { TC } & \text { Total Cholesterol } \\ \text { TG } & \text { Triglyceride } \\ \text { VLDL } & \text { Very Low Density Lipoprotein }\end{array}$

